\title{
Libros, cartas, lecturas: La revisión de la historia en Argentina y Paraguay a través de los intercambios epistolares entre David Peña y Juan E. O'Leary*
}

\author{
Books, letters, lectures: Revision history in Angentina and Paraguay \\ through epistolary Exchanges between David Peña and Juan E. O'Leary
}

\author{
Liliana María Brezzo \\ lilianabrezzo@arnet.com.ar \\ Investigadora Independiente CONICET \\ IH, UCA - IDEHESI / CONICET \\ Av. Pellegrini 3314, 2000 ROSARIO \\ Argentina \\ María Gabriela Michelett \\ gabimiche@yahoo.com.ar \\ Investigadora Adjunta CONICET \\ Profesora Adjunta UCA \\ IH, UCA - IDEHESI / CONICET \\ Av. Pellegrini 3314, 2000 ROSARIO \\ Argentina
}

\section{Resumen}

El presente artículo se centra en el análisis del intercambio epistolar mantenido entre el argentino David Peña y el paraguayo Juan E. O'Leary, dos historiadores que hacia principios del siglo XX se embarcaron en un proceso de revisión de la historia de sus respectivos países. El estudio de los ritmos de ese intercambio permite, a la vez, considerar algunos rasgos de las biografías que produjeron sobre Juan Facundo Quiroga y Francisco Solano López ysopesar la influencia que la obra del argentino tuvo en la práctica de la historia del paraguayo, así como también aportar datos a un mejor conocimiento sobre los modos en que se difundieron y circularon por la región las obras de historiadores pertenecientes a diversas naciones del espacio rioplatense. Desde el plano metodológico, los resultados a los que se arriba contribuyen a destacar la importancia de las cartas intercambiadas entre historiadores para esclarecer sus concepciones del pasado y su utilidad para contrastarlas con los discursos históricos producidos en el espacio público.

\section{Palabras-clave}

Cartas; Historiadores; Historiografía.

\begin{abstract}
This paper focuses on the analysis of the exchange of letters between the Argentine David Peña and the Paraguayan Juan E. O'Leary, two historians that by the early twentieth century embarkedon aprocess of reviewing the history of the irrespective countries. The study of therates of that exchange allows, in turn, consider some features of the biographies that they produced about Juan Facundo Quiroga and Francisco Solano Lopez, and balance the influence that the work of the Argentinehadin the historiographical practice of the Paraguayan, as well asprovide information to a better understanding of the ways in whichthe works of historians belonging to the nations of the River Plate area spread throughout the region and circulated. From the methodological level,the results contribute to highlight the importance of the letters exchanged between historians to clarify their conceptions of the past and its usefulness to contrast with historical discourses producedin the public space.
\end{abstract}

Keywords

Letters; Historians; Historiography.

Recibido el: 31/8/2015

Aceptado el: 8/3/2016

${ }^{*}$ IH, UCA - IDEHESI / CONICET. 
Entre 1907 y 1928 el historiador argentino David Peña (1862-1930) y el paraguayo Juan E. O'Leary (1879-1969) mantuvieron un sostenido contacto epistolar e intercambiaron novedades bibliográficas. Las cartas cruzadas, en tanto discursos producidos en la esfera privada, son un testimonio elocuente del rastro histórico que ellos mismos han dejado; ponen de manifiesto sus inteligencias, sus preocupaciones, sus aspiraciones. $Y$ ese descubrimiento es importante. Al mismo tiempo el análisis del intercambio epistolar pretende complejizarla filiación del revisionismo histórico en Argentina, su recepción en otros espacios nacionales y comparar sus peculiaridades. ${ }^{1}$ De manera particular interesa, en este caso, llamar la atención acerca del influjo que la obra de David Peña tuvo en la práctica de la historia del joven escritor paraguayo, así como también aportar datos a un mejor conocimiento acerca de los modos en que se difundieron y circularon por la región las obras de historiadores pertenecientes a diversas naciones del espacio rioplatense.

De acuerdo con las pruebas disponibles, es posible identificar, según el rango cronológico mencionado, tres momentos de especial densidad en los contactos epistolares entre Peña y O'Leary, cuyos contenidos se examinan en los siguientes apartados.

Además de analizar las características de ese intercambio, este trabajo pretende dar cuenta de algunos rasgos de las biografías que produjeron en torno a actores controvertidos de la historia de sus respectivos países: Juan Facundo Quiroga: contribución al estudio de los caudillos argentinos (1906), de David Peña, y El Mariscal Solano López (1925), de Juan E. O’Leary.

En el plano metodológico se procura resaltar la importancia de las cartas intercambiadas entre historiadores para esclarecer sus concepciones del pasado y su utilidad para contrastarlas con los discursos históricos producidos en el espacio público; en particular, en este caso, para poner en relación los procesos de revisión de la historia que se iniciaron contemporáneamente en Argentina y en Paraguay. ${ }^{2}$

El estudio se apoya, centralmente, en los documentos que componen el Fondo David Peña del Archivo y Biblioteca de la Academia Nacional de la Historia de la República Argentina, en los manuscritos incluidos en el Legajo David Peña del Archivo del Museo Histórico Provincial de Rosario "Dr. Julio A. Marc", y en la Colección Juan E. O'Leary, depositada en la Biblioteca Nacional del Paraguay. En el caso de este último país, el hallazgo y la reciente organización

\footnotetext{
${ }_{1}^{1}$ Puede sostenerse que desde fines del siglo XIX y con los primeros compases del siglo XX, de la mano de obras como las de Adolfo Saldías, Ernesto Quesada y David Peña emergió, en Argentina, una revisión de la lectura clásica de diversos procesos del pasado argentino, incluida la Guerra del Paraguay. En efecto, en el estudio de Quesada La Política argentino-paraguaya aparecen la mayoría de los tópicos que desarrollará in extenso el revisionismo posterior. En Uruguay, por la misma época principió un impulso de revisión de la lectura clásica de la guerra de la mano de Luis Alberto de Herrera, autor de La tierra charrúa (1901) y de La diplomacia oriental en el Paraguay (1909). Sobre la dinámica de esta lectura pueden verse los estudios de María Laura Reali (REALI 2006). Resulta conveniente señalar que la revisión de la historia que aquellos primeros "revisionistas" argentinos promovieron, en tanto que operación historiográfica -la aplicación de un método basado en la objetividad histórica y la compulsa documental-, se diferenció de la operación política que abiertamente supuso el revisionismo de los años treinta como impugnación del liberalismo y democratismo del sistema republicano argentino (DEVOTO y PAGANO 2010, p.203-205; CHIARAMONTE 2013, p. 145-179). 2 En años recientes han sido desenvueltos diversos argumentos en torno a los epistolarios como herramientas de análisis historiográfico (MESTRE SANCHÍS 2000, p. 13-26; ORTEGA 1991; BORKOSKAY 2002, p. 27-45).
} 
de archivos personales de historiadores paraguayos -además del de O'Leary se han recuperado los de Carlos Pastore (1907-1996) y Rafael Eladio Velázquez (1926-1994) como así también papeles privados de José Falcón (1810-1881) y Blas Garay (1873-1899)-constituyen, sin duda, un corpus de apreciable valor no únicamente para el análisis del historiador, su contexto histórico y su influencia en los ámbitos más dispares de la vida pública sino, de manera particular, para el estudio de las tendencias ideológicas que condicionaron su labor histórica.

\section{Primer momento: Juan Facundo Quiroga y Francisco Solano López}

El contacto epistolar entre Juan E. O'Leary y David Peña comenzó en el mes de enero de 1907 en ocasión de divulgarse en Paraguay el texto sobre Juan Facundo Quiroga que había sido editado unos meses antes en la capital argentina. ${ }^{3}$ Para comprender el alcance de la proyección lograda en corto tiempo por el libro de Peña conviene recordar algunos antecedentes.

En 1903, David Peña había dictado en la recientemente creada Facultad de Filosofía y Letras (1896) de la Universidad de Buenos Aires quince conferencias muy resonadas por la defensa que en ellas se realizaba del caudillo riojano, a contrapelo de la obra de Domingo F. Sarmiento. Para ese entonces, Peña se desempeñaba como profesor suplente de Historia Argentina, cargo que ocupaba desde que regresara por última y definitiva vez a establecerse en la ciudad de Buenos Aires, ya sobre el final del siglo XIX. Formaba parte del grupo de políticos e intelectuales rosarinos -como Estanislao Zeballos, Gabriel Carrasco, Rodolfo Rivarola- que habían llegado a la capital del país por las mayores posibilidades que ésta ofrecía. En años anteriores, entre mediados de la década de 1880 y principios de la siguiente, Peña había realizado una encomiable tarea procurando promover la creación y desarrollo de diversos emprendimientos e instituciones de carácter cultural en Santa Fe y Rosario. Con desigual éxito, había fundado el periódico Nueva Época en Santa Fe y La Época y Revista Argentina en Rosario, y había impulsado el establecimiento de una biblioteca popular en la capital santafesina. También había incursionado en el género dramático, convirtiéndose en un reconocido autor teatral.

Debido al interés que habían despertado las conferencias sobre Quiroga, su autor decidió convertirlas al formato de libro, con el fin de darles una mayor difusión y alcanzar un público más amplio que el que se había llegado hasta los claustros universitarios atraído por los rumores de que su tesis entraba en abierta polémica con la versión canónica que la historiografía liberal había consagrado acerca de Quiroga. Para ello revisó los manuscritos y les realizó algunas modificaciones y agregados, dándolos a la Casa de Coni Hermanos para su impresión. ${ }^{4}$ En mayo de 1906 el libro estuvo listo, y los anuncios periodísticos pusieron a la sociedad porteña al tanto de su aparición, con sugerentes comentarios que animaban a su lectura. Tal como sostenía una nota publicada en El Tiempo, por ejemplo,

\footnotetext{
${ }^{3}$ El contexto de producción y la recepción de la obra de David Peña los hemos estudiado en MICHELETTI 2015. ${ }^{4}$ Archivo del Museo Histórico Provincial de Rosario "Dr. Julio A. Marc" (AMHP), Documentos manuscritos clasificados por Legajos personales: David Peña, Caja 1, "Juan Facundo Quiroga. Conferencias pronunciadas en la Facultad de Filosofía y Letras, con ampliaciones y notas".
} 
"el nuevo libro está llamado a producir controversias históricas dado el nuevo aspecto en que presenta el doctor Peña a Facundo". ${ }^{5}$ La obra de Peña fue pronto reseñada en diversos medios y contó tanto con críticos entusiastas como con detractores. Algunos de estos últimos, especialmente filosos, cargaron no sólo contra el discurso historiográfico que proveía el libro, sino también contra su autor: "Engañoso en su forma, el libro de usted, doctor Peña, nos presenta al caudillo riojano sublimado por los derroches de su fantasía. [...] iMal filósofo y peor historiador, el que para levantar a un caído, necesita vilipendiar a los que están en las alturas!"6 La figura de Peña cobró notoriedad, y unos pocos meses después el rosarino ingresaba como miembro de número a la Junta de Historia y Numismática Americana (posterior Academia Nacional de la Historia de la Argentina), no sin dejar de producir su admisión un sacudón en la institución, que sufrió la renuncia de su vicepresidente primero, José Juan Biedma, ofuscado porque se permitiera el ingreso al defensor del caudillo. Alentado por elogios y ataques, el libro se distribuyó rápidamente por todo el país, tal como lo atestigua un afiche impreso por la librería "Hijos de José Alsina y Cía." de Paraná (Entre Ríos), que ofrecía enviarlo a cualquier punto de la República. ${ }^{7}$ Tanto, que fue necesario hacer una nueva edición ese mismo año de 1906, y otra más al año siguiente. Con este mismo impulso cruzó los límites nacionales y recaló en las librerías de Asunción, de donde llegó a manos de Juan E. O'Leary quien, para entonces, era ya una figura reconocida e influyente en el espacio cultural.

En esos primeros años del siglo veinte era posible identificar en el Paraguay una elite político cultural que había ido conformándose en el período de la posguerra de la Triple Alianza -fundamentalmente, pero no sólo- con egresados del Colegio Nacional y de la Facultad de Derecho que pasaría a denominarse Generación del 900. La conformarían, entre otros, Blas Garay, Manuel Domínguez, Fulgencio R. Moreno, Arsenio López Decoud, Manuel Gondra, Ignacio Pane, Ricardo Brugada (h), Eligio Ayala, Teodosio González, Alejandro Guanes, Juan Francisco Pérez Acosta y el mismo Juan E. O'Leary.El escritor Raúl Amaral reunió, en sucesivos trabajos de investigación literaria, a 26 nombres principales de los cuales 8 conformaron, según su perspectiva, por sus ideas y su producción, el núcleo sustancial del Novecentismo: Arsenio López Decoud, Manuel Domínguez, Manuel Gondra, Fulgencio R. Moreno, Blas Garay, Eligio Ayala, Juan E. O'Leary e Ignacio A. Pane (AMARAL 2006; GOMEZ LEZ; ZARZA 2013).

Políticamente, algunos de estos letrados adhirieron al Partido Colorado, como Blas Garay, Fulgencio Moreno, Manuel Domínguez, en tanto otros se mostraron identificados con los principios del Partido Liberal como Eligio Ayala, Manuel Gondray Juan O'Leary.

Este grupo comenzó a vehiculizar sus afanes culturales a través de distintos canales. El principal fue la prensa, pero también se destacaron algunas revistas,

\footnotetext{
${ }^{5}$ Academia Nacional de la Historia, Fondo David Peña (ANH-FDP), Libro 3, "Juan Facundo Quiroga. El libro del Dr. David Peña".

${ }^{6}$ ANH-FDP, Caja 4, Ricardo Adriano Paz, "Tribuna libre. Sobre Facundo", La Razón, Buenos Aires, 4 de enero de 1907.

7 ANH-FDP, Libro 3, "Acaba de aparecer".
} 
las cuales, a partir de finales del siglo diecinueve, habían ido adquiriendo una particular relevancia. Entre estas figuraba la Revista del Instituto Paraguayo, que circularía entre 1896 y 1908 y estaba dirigida a un público culto. Efectivamente, el 26 de junio de 1895 un núcleo de los jóvenes novecentistas junto a otras figuras influyentes de la sociedad asunceña fundó el Instituto Paraguayo. En un comienzo sus impulsores se limitaron a enunciar entre sus propósitos el fomento del estudio de la música y el desarrollo de la literatura, proporcionar la enseñanza de idiomas y estimular los ejercicios físicos por medio de la gimnasia y la esgrima. Sin embargo, las cuestiones sobre el pasado pasaron a constituirse, al poco tiempo, en materia predominante de las conferencias, de los discursos y de otras actividades llevadas a cabo por la institución las que, en todos los casos, suponían un punto de referencia, un indicador preciso de los rumbos temáticos consagrados por esa élite intelectual; se impuso entonces la necesidad de divulgar tales emprendimientos a través de una revista. Así, en octubre de 1896 apareció el primer número; definida como una publicación de carácter esencialmente científico pasó a subtitularse, poco tiempo después, "Historia, Ciencias, Letras", haciendo referencia a sus principales contenidos. Fue la publicación más importante de esos años y en sus números podían leerse aportes de Victorino Abente, Rafael Barrett, Jean-Paul d'Aile (Casabianca), Manuel Gondra, Manuel Domínguez e Ignacio A. Pane, entre otros autores significativos (BREZZO 2011a).

En los mismos años en que se editaba la revista del Instituto, comenzaron a circular otras publicaciones con similares pretensiones científicas como la Revista de la Universidad Nacional y la Revista de Agronomía y de Ciencias Aplicadas, dirigida por Moisés Bertoni.

Al mismo tiempo, aquellas convivieron con otras revistas dirigidas a un público selecto, pero más aligeradas, con grabados de paisajes y de personajes, anecdotarios y textos breves. José Segundo Decoud, uno de los intelectuales y políticos más influyentes de la época poseía una de las principales bibliotecas del país; si se repasa su Catálogo es posible dar cuenta de algunas de esas publicaciones, como Ilustración Paraguaya, La Revista Cómica, La Rivista Italiana. Coloniale, comerciale, sociale, The Paraguay Review. Paraguayische Nachrichten, Tribuna de los intereses del Paraguay, La Revista del Paraguay, Crónica y Anales del Gimnasio Paraguayo, todas publicadas entre las últimas décadas del siglo XIX y la segunda década del siglo XX (CENTURIÓN 1961; GONZALEZ DE BOSIO 2008).

El 10 de septiembre de 1900, O'Leary fue designado profesor de Historia Americana y Nacional en el Colegio Nacional de Asunción y en el transcurso del mismo año inició sus colaboraciones en el diario La Patria, dirigido por Enrique Solano López.

Así, habiendo superado escasamente los veinte años, comenzó a dedicarse a la enseñanza de la Historia y a adquirir cierto protagonismo en las actividades periodísticas y culturales de la capital paraguaya (BREZZO 2011b).

En La Patria principió la publicación, a partir del 2 de mayo de 1902, aniversario de la batalla de Estero Bellaco de la guerra contra la Triple Alianza, 
de una serie de 26escritos de índole histórica bajo el título general de Recuerdos de Gloria, cuyas entregas se prolongaron hasta el año 1904. El autor declaró que la principal intención que le movió a redactarlos fue el "de exaltar el heroísmo del pueblo vencido en una lucha desigual" y "exponer a las nuevas generaciones las hazañas de los héroes de la Guerra del Paraguay contra la Triple Alianza" quienes "dormían casi olvidados de la patria, después de haber escrito en sangre la estupenda epopeya de aquella defensa sobrehumana" (O'LEARY 2008, p. 35).

Poco después de principiar estas entregas, protagonizó con el prestigioso abogado paraguayo Cecilio Báez (1862-1941), la primera polémica sobre la historia del Paraguay. A través de las columnas de La Patriay El Cívico la disputa se inició en el mes de octubre de 1902 y se extendió hasta el 14 de febrero de 1903; fue la primera vez que la sociedad paraguaya participó, directa e indirectamente, en un debate sobre su pasado (SCAVONE YEGROS; BREZZO 2012).

Respecto a la guerra contra la Triple Alianza, Báez la explicaba como un efecto del propio sistema tiránico, que tuvo su origen en la época colonial y se consolidara durante los gobiernos de Francia y de los dos López:

La guerra - sostenía - se hizo de exterminio para el Paraguay, no solamente por obra de los aliados, sino también por obra del mismo López. Los déspotas siempre quieren aparecer como intérpretes de la voluntad nacional o sirviendo los intereses de la Nación. Cualquier hombre de sentido común comprenderá que López ni debió intervenir en el conflicto uruguayo-brasilero ni mucho menos provocar la guerra. Tal fue el desenlace de la tiranía paraguaya. Fue el sacrificio de todo un pueblo. El país quedó arruinado y desmembrado. Toca a la nueva generación reparar lo perdido, por la educación, por el trabajo, por la práctica de la libertad, por el concurso del elemento extranjero, pero principalmente por la educación, para que al rebaño humano lo reemplace un pueblo consciente de sus derechos, que haga imposible la vuelta de las omnímodas y embrutecedoras dictaduras (SCAVONE YEGROS; BREZZO 2012, p. 98).

O'Leary, por su parte, lo enfrentó con un discurso completamente opuesto desde las columnas de La Patria, centrándose en un pasado heroico y glorioso, en el que la sociedad paraguaya vivía feliz y próspera hasta que una serie de causas exógenas la habían condenado a su actual postración. Dedicó a cada episodio del acontecimiento bélico un artículo completo en un esfuerzo hermenéutico dirigido a mostrar

[...] quien fue la mano negra que arrojó, sobre el Plata y el Paraguay, el huracán de muerte que hizo añicos de nuestra pasada grandeza y poderío. Diremos que la intervención brasileña en el Uruguay y la guerra de 1865 fue el lógico desenlace de la política absorbente, de las miras ambiciosas del Imperialismo. En efecto, no de otro modo podían concluir las añejas pretensiones del único imperio de la América del Sud -verdadero parásito adherido al suelo del nuevo mundo- que en todos los momentos de su historia amenazó a sus vecinos y más que amenazó, asaltó con invasiones verdaderamente bárbaras, como las de sus mamelucos que han dejado triste memoria en los países limítrofes ¿Con qué país vecino no tuvo disensiones seculares por la cuestión de límites? ¿A qué país vecino no arrebató el Brasil inmensas zonas de territorio? (SCAVONE YEGROS; BREZZO 2012, p. 98). 
Con estos contenidos fue desplegando en el transcurso de la disputa un conjunto de argumentos con el propósito de demostrar que la guerra tuvo su origen en las maquinaciones del Imperio del Brasil y en la complicidad del gobierno argentino de Bartolomé Mitre, y para salir victorioso en la polémica. El veinteañero letrado, que durante la controversia firmó todos sus artículos con el seudónimo de Pompeyo González, se hizo a un más conocido; sus seguidores comenzaron a identificarse como pompeyistas y su revisión de la historia clásica de la guerra contra la Triple Alianza comenzó a ser denominada como pompeyismo. ${ }^{8}$

Pues bien, poco después, a mediados de 1903, jaqueado por sus escisiones internas y por una vasta coalición de intereses sociales y económicos que se pusieron en su contra, empezó a tomar forma un vasto movimiento revolucionario en Paraguay contra el régimen del partido Colorado. Un grupo numeroso de personas estaba dispuesto a convertirse en partidario de una revuelta que se preparaba en Buenos Aires y en Asunción. Liderada por figuras conspicuas del Partido Liberal como Cecilio Báez y Benigno Ferreira y por jóvenes entusiastas como Manuel Gondra, José y Modesto Guggiari, Gualberto Cardús Huerta y Adolfo Riquelme, se inició una larga campaña para vencer la resistencia de los gubernistas en diversas zonas del país, en cuyo transcurso se sucedieron varios encuentros armados, hasta que la caída de la ciudad de Encarnación señaló la derrota definitiva del coloradismo. La revolución tuvo su desenlace en Puerto Pilcomayo, en el mes de diciembre, donde Juan Antonio Escurra y el jefe del gobierno rebelde, Benigno Ferreira, acordaron designar un presidente 20 provisorio y constituir un gabinete mixto. o'Leary, aunque identificado con el Partido Liberal, no participó en el movimiento, asumiendo una conducta pasiva y prescindente. El triunfo de la revolución hizo, entonces, que quedase enfrentado con su partido en el que militaban algunos de sus más implacables enemigos intelectuales, como Cecilio Báez. En lo inmediato, el nuevo orden político condicionó que O'Leary se viera reducido al usufructo de una sola cátedra en el Colegio Nacional y marcó un momentáneo final a la colaboración en la prensa y a su activa participación cultural. Para paliar las consecuencias económicas de la situación, pero también como una especie de exilio y de resistencia al orden liberal, a comienzos del año 1906 se fue a vivir con su familia a San Lorenzo. La estancia en ese pueblo -muy cercano a la capital- tendría en la vida intelectual de O'Leary una notable densidad. Allí trabó vínculos de amistad con los reconocidos escritores Viriato Díaz Pérez, Hérib Campos Cervera (padre) y Gregorio Benites. Varias veces a la semana O'Leary viajaba por tren a Asunción para visitar y conversar con los amigos y colegas como Enrique Solano López

\footnotetext{
${ }^{8}$ Durante estos años de juventud como escritor, O'Leary utilizó varios seudónimos: primero hizo uso de Diego de la Escosura y luego apareció Justas N. Zambrana. En la polémica con Cecilio Báez firmó sus artículos con un tercer seudónimo, el de Pompeyo González. Fue con éste con el que se hizo conocido. Según testimonio de sus amigos "no había veterano de la guerra que no hablara de Pompeyo González sin religiosa unción". Parece posible vincular, de este modo, los contenidos historiográficos del pompeyismo con una especie de proto-revisionismo histórico o, más precisamente, con algunos de sus temas. De hecho, el Mariscal Francisco Solano López no fue la figura central del debate O'Leary- Báez. Se ha desenvuelto esta lectura en (BREZZO 2011a). Autores dedicados a las relaciones entre historia y memoria en el Paraguay, como Luc Capdevila, han subrayado, asimismo, que a inicios del siglo XX el análisis de la trayectoria del Mariscal seguía siendo "ambiguo, incluso para los intelectuales nacionalistas. Las posiciones de Blas Garay, de Juan O'Leary, así como las de Manuel Domínguez en 1900 no estaban definidas" (CAPDEVILA 2010, p. 205).
} 
e Ignacio Pane -con quienes tramitaba la reapertura del diario La Patria-y con Juan Silvano Godoi, con quien compartía tertulias en el Archivo Nacional. ${ }^{9}$

Pues bien, fue en ese contexto cuando, a comienzos del año 1907, se produjo el inicio de los vínculos con David Peña, luego de que O'Leary, en uno de esos semanales viajes a Asunción localizara en una librería un ejemplar del estudio sobre Juan Facundo Quiroga. Hay que mencionar que, aun en medio del difícil proceso de reconstrucción social que atravesaba el Paraguay, el negocio editorial cobraba impulso. En la capital paraguaya sobresalían tres librerías: la de los hermanos Muñoz, la de Uribe y la librería de Puigbonet. Las ediciones que se exhibían en los respectivos escaparates provenían de los recientemente instalados Talleres Nacionales de H. Kraus, estrechamente vinculados con la impresión de textos históricos y jurídicos (VELÁZQUEZ 1999) a las que luego se sumaron las provenientes de otras firmas de la plaza como La Mundial, La Colmena, la tipografía de Quell y la de Zamphirópolos. Aunque no se dispone de pruebas suficientes, es probable que O'Leary hubiera comprado el libro de Peña en el negocio de los hermanos Muñoz, a quienes conocía y cuya librería frecuentaba a menudo.

Luego de leer el libro sobre Quiroga, O'Leary se ocupó de consignar, en unos apuntes íntimos, la impresión que le produjo:

Hermoso libro. Su lectura me ha dejado una grata impresión. Quiroga resulta un prócer argentino. Desvanecida la sangrienta leyenda forjada por Sarmiento queda la vida del grande hombre, reducida a sus justas proporciones. Facundo ya no es el bárbaro, sediento de sangre, corrompido, enemigo jurado de la civilización como lo pintó el asesino de Peñaloza, el "doctor de Michigan". Queda, como dice Peña, el general Juan Facundo Quiroga, representante nato de las provincias y precursor de Urquiza en la obra de la organización nacional. La teoría de Peña se puede fácilmente aplicar al Mariscal López. Un libro así de reivindicación es mi más constante preocupación. Alguna vez lo haré.

Francamente me seducen los hombres que, como David Peña, defienden a los perseguidos, a quienes se ceba el odio inconsciente de las multitudes. David Peña ha vindicado a Alberdi levantándole un monumento en Buenos Aires. Y ahora vindica a Quiroga. Los dos hombres más odiados de su país. Tiene que ser un alma fuerte. Y son pocos en la Argentina: Saldías y él. Y si Rosas y Quiroga tienen sus panegiristas ¿No podrá tenerlos el Mariscal López? López no cometió ni la millonésima parte de los crímenes de Rosas, ni anarquizó a su patria como Quiroga. Loco por el desastre, traicionado, vendido, cometió actos de crueldad que condeno, pero que son perfectamente explicables. Derramó sangre paraguaya pero en defensa de la patria por cuya causa pereció en el último campo de batalla. Es mil veces más grande que Rosas y Quiroga juntos. Con razón dijo Alberdi que no tenía un igual en la América (BNP-CJEO, Diario de Juan E. O'Leary, vol. 1).

\footnotetext{
${ }_{9}^{9}$ Biblioteca Nacional del Paraguay, Colección Juan E. O'Leary (en adelante BNP- CJEO), Correspondencia oficial y privada. Carpetas XXXI y XXXII. Interesa resaltar que entre los corresponsales de O'Leary en la primera década del siglo veinte figuran autores que pergeñaban lecturas opuestas a las clásicas sobre la guerra del Paraguay y la historia de las relaciones entre los países del Plata, como Ernesto Quesada, en Argentina y el uruguayo Luis Alberto de Herrera. Con este último inició una correspondencia fluida e ininterrumpida hasta el fallecimiento de Herrera, en 1959.
} 
Al mismo tiempo remitió la primera carta a David Peña en la que, luego de presentarse, le ponía de manifiesto la identificación de sus ideas con el espíritu que, según entendía, había inspirado el estudio sobre el caudillo argentino:

\begin{abstract}
Años hace que me consagro a una obra semejante desde las columnas de la prensa de mi país. No le asombre, pues, mi actitud, que ella es hija del entusiasmo que no puede menos que producirme esta afinidad entre su pensamiento y el mío. Cuan pocos son los hombres que, como usted, se atreven a desafiar los prejuicios en nombre de la justicia histórica. Yo que he combatido por todas partes en mi país brego en defensa de las glorias de mi patria, aprecio en su justo valor su actitud. Yo se las luchas, los trabajos, las amarguras que importa este noble apostolado. Créame, pues, su admirador y cuénteme en el número de los que le acompañan en su cruzada de vindicación iniciada con el monumento al más grande argentino -Alberdi- y meritoriamente continuada en su último libro (BNP-CJEO, Correspondencia Oficial y Privada, Carpeta XXX, Asunción, enero de 1907).
\end{abstract}

Merecen ser ponderados estos escritos porque, según entendemos, permiten fechar el origen de uno de los atributos principales de la forma de hacer historia de O'Leary: la vindicación. Aun no se había lanzado a la acción reivindicatoria del Mariscal Francisco Solano López, pero el influjo que la lectura del libro de Peña ejerció sobre él pone de manifiesto que comenzaba a explicarlo.

No se dispone de la respuesta de David Peña a esta carta. De hecho, todo indica que no hubo continuidad en la relación epistolar hasta bastantes años después, cuando se revivieron en Buenos Aires las controversias, iniciadas en las últimas décadas del siglo XIX, en torno a otro cuestionado actor de la historia de la guerra: Juan Bautista Alberdi.

\title{
Segundo momento: Juan Bautista Alberdi
}

A raíz de la ordenanza del 28 de noviembre de 1919 del Concejo Deliberante de la ciudad de Buenos Aires de darle a una calle el nombre de Alberdi, el diario La Nación hizo pública su objeción fundándose en la "traición" que había significado, según sostenía, la defensa intelectual de la causa paraguaya puesta de manifiesto en sus escritos divulgados en el transcurso del conflicto y en la correspondencia que había mantenido con el presidente paraguayo Francisco Solano López (RUBIO GARCÍA 2010). David Peña replicó a La Nación desde las columnas de La Prensa y La Época, refutando la acusación con la que se cuestionaba al polígrafo tucumano. Sostuvo que:

El odio a Alberdi forma parte del culto mitrista [...] A medida que se eleva el nivel de la cultura pública, en proporción a los progresos del criterio ilustrado y científico de la república, se exalta y consolida la figura reflexiva del pensador más robusto y adelantado que ha tenido la organización nacional. Correlativamente, otros valores ficticios descienden, descienden [...] La obra original y profunda de Alberdi se estudia con interés y respeto en las universidades argentinas, donde se le discierne el alto valor jurídico que le corresponde (La Época, Buenos Aires, 30 de noviembre de 1919). 
Para reforzar la defensa desplegada por Peña, O'Leary le envió una breve nota de adhesión y publicó en Asunción un artículo titulado "Mitre contra Alberdi". Se trató de un texto extenso e intenso en el que procuraba, como se ha apuntado, ratificar la defensa que Peña llevaba a cabo en la capital argentina. Entre los argumentos desenvueltos frente a quienes calificaban a Alberdi como traidor a la patria, O’Leary escribía:

Por lo demás, es del caso preguntar dónde estaba la patria en aquellos momentos y quiénes eran los que estaban, realmente, en inteligencia con el enemigo.

La patria no eran, seguramente, Mitre y sus corifeos, únicos que sostenían la guerra contra el Paraguay y el sometimiento servil a la política imperialista del Brasil.

La patria era el país entero sublevado contra la política de Mitre, era toda la República Argentina, hostil a la guerra. Y los enemigos, los verdaderos enemigos en armas contra la patria eran los que arrastraban al país a una empresa vergonzosa, sirviendo los intereses del adversario tradicional y poniendo al Paraguay en el caso de tomar las armas en defensa de su vida amenazada. No eran traidores los provincianos que se sublevaron en Basualdo y en Toledo para no ir al Paraguay; no eran traidores los Saa, los Varela, todos los caudillos del interior que levantaron banderas de revolución, y durante toda la guerra protestaron, con las armas en la mano, contra el bárbaro exterminio de un pueblo; no eran traidores los contingentes provincianos que se dispersaban en el camino o eran embarcados a balazos en los buques de la escuadra; no eran traidores los Guido, los Andrade, los Navarro Viola, todos los que en la prensa porteña defendían al Paraguay o condenaban a Mitre; no era traidor Adolfo Alsina diciendo que se hacía una "guerra carnicera", ni Oroño pidiendo la paz en pleno parlamento, ni Quintana Ilamando "guerra desautorizada" a la guerra del Paraguay; no era traidor el mismo Urquiza haciendo una resistencia pasiva a la campaña; no eran traidores, en fin, todos los que de un confín a otro de la República estaban con el Paraguay o contra la funesta camarilla de Buenos Aires, coincidiendo en la condenación de una empresa que, al decir del mismo Mitre, "nunca fue realmente popular. Si esto no fuera así, resultaría que, junto con Alberdi, ifueron traidores todos los argentinos! (Patria, Asunción, 13 de diciembre de 1919).

Llegados a este punto conviene hacer referencia al lugar que O'Leary le otorgaba a Alberdi en su lucha contra el "mitrismo", al que definía como expresión de una "oligarquía omnipotente que había embargado la soberanía de las provincias del interior". Había conocido los textos del tucumano a favor de la causa paraguaya a través del diplomático paraguayo Gregorio Benites, quien, durante los años de la guerra contra la Triple Alianza, estuvo al frente de la legación paraguaya en Francia. En esas circunstancias Benites conoció a Alberdi con quien anudó una sólida amistad $y$, en los veinte años siguientes, mantuvo una fluida correspondencia.

Antes de fallecer, en el año 1909, Benites le legó a O'Leary su archivo, que contenía varios centenares de piezas epistolares que le dirigiera Alberdi. A partir de estas circunstancias, el historiador paraguayo hizo uso de la figura del argentino y de su posición intelectual durante la guerra para entretejerlo en su operación de revisión de la historia, en la cual fue presentado como un admirador de López y "justificador de sus crueldades" (BREZZO 2012). 
Pues bien, en el contexto de la controversia suscitada en Buenos Aires, Peña entró también en contacto epistolar con un discípulo de O'Leary, Juan Stefanich (1889-1976), a la sazón presidente del Centro de Estudiantes de Derecho de la Universidad Nacional de Asunción y que, con el correr de los años, se convertiría en un abogado, periodista y político paraguayo de fuerte influjo en la posguerra del Chaco para luego, a partir de 1937, vivir exiliado en Buenos Aires hasta su fallecimiento en 1976 (CABALLERO CAMPOS 2011). En una carta del año 1919 que se conserva en el Fondo Peña de la Academia Nacional de la Historia puede leerse que Peña elogia al universitario por la decisión de fundar una Biblioteca y llevar adelante una empresa editorial. Algunos conceptos deslizados por éste a raíz de este emprendimiento universitario son particularmente significativos en el sentido de reclamar una historiografía paraguaya en torno a la guerra de la Triple Alianza que, a la vez que documentada y científica, aportase una visión alternativa desde la perspectiva de los vencidos, como una manera de colaborar a que se alcanzase la verdad histórica sobre el conflicto bélico que enfrentó a los países sudamericanos a mediados del siglo XIX: El Paraguay debe a la América y al mundo, especialmente, la bibliografía
de la Guerra con la Triple-Alianza y ojalá que en esa bibliografía figurara la
histórica, la documentada, la serena, para que sirviera a las conciencias
que reclaman y reclamarán en lo futuro la verdad (ANH-FDP, Caja 2, De
David Peña a Juan Stefanich, Buenos Aires, abril 20 de 1919).

En la misma carta David Peña enlaza ese necesario proceso de revisión de la historia paraguaya, con el de reivindicación que él mismo asumió personalmente en torno a la figura de quien fuera su maestro y padre espiritual, Juan B. Alberdi, y aprovecha para anunciar a Stefanich que se ha conformado en Buenos Aires un comité de carácter nacional con el propósito de rendir homenaje y promover la erección de un monumento al inspirador de la Constitución Nacional argentina.

Invitado por Peña, Juan Stefanich junto a otros compañeros paraguayos, participó en Buenos Aires de ese homenaje, en el mes de mayo de 1920, ocasión en la que pronunció en la Facultad de Filosofía y Letras de la Universidad de Buenos Aires una conferencia que tituló "El Paraguay: su historia y sus hombres". Tras su estadía en la capital argentina, le escribió a Peña para expresarle su agradecimiento por la acogida que le dispensara. Dada la distancia generacional, reconoce en Peña a un "padre", a un "amigo", a un "protector" y a un "consejero", y lo pone al tanto del entusiasmo con el que el público de Asunción ha reaccionado frente a las noticias y telegramas llegados desde Buenos Aires.

En particular, Stefanich agradece a Peña por los elogiosos conceptos que sobre la Delegación de Paraguay le ha expresado en una carta a Juan O'Leary, de lo cual se puede deducir que el contacto entre Peña y Stefanich había surgido de la relación en común con el historiador paraguayo. El vínculo intelectual e ideológico entre Stefanich y su maestro O'Leary queda reforzado en la carta por la alusión que hace el primero a algunas críticas que también han existido por parte de la prensa liberal asunceña, y en particular por el diario El Liberal, que ha descalificado a los delegados paraguayos enviados a Buenos Aires, tildándolos 
de "víctimas e instrumentos del señor O'Leary". Stefanich le anuncia a Peña, además, que publicará sus crónicas de viaje en El Diario y que luego las editará en folleto (ANH-FDP, Caja 2, De Juan Stefanich a David Peña, Asunción, mayo 21 de 1920). Efectivamente, poco después aparece publicado el libro de Stefanich, titulado Alberdi, la Argentina y el Paraguay: al margen de una misión, de 199 páginas (STEFANICH 1920). En él, un capítulo se dedica específicamente a: "La delegación a Buenos Aires", en donde Stefanich brinda una versión testimonial de su viaje. ${ }^{10}$

El homenaje brindado a Alberdi en 1920 habría obrado como incentivo para la reflexión historiográfica. Además del mencionado libro de Stefanich, fueron publicados en Buenos Aires: ¿Alberdi fue traidor? y El gran americano Juan Bautista Alberdi, de Adolfo S. Carranza, antecedido este último por una carta prólogo de David Peña. De ese mismo año data, además, la publicación de una nueva edición de las Obras selectas de Juan B. Alberdi, en 18 tomos, con introducción y selección a cargo de Joaquín V. González. Y también parece haber propiciado la reanudación del contacto epistolar entre O'Leary y Peña. En efecto, el 19 de mayo de 1920 el primero le escribía una carta al argentino encabezándola "mi querido amigo". La epístola demuestra que, no obstante, el inicial intercambio de 1907, no se habían conocido personalmente en los años que siguieron y tampoco habrían cultivado el intercambio promovido por O' Leary:

¡Amigo, sí! Hace catorce años que lo soy ¿Recuerda Ud. la carta que le escribí entonces, después de leer su libro sobre Facundo? No importa que no nos hayamos encontrado en ninguna encrucijada de la vida. No importa que nunca hayamos tenido ocasión de darnos un abrazo fraternal. El culto a Alberdi nos vinculaba y nuestro común apostolado justiciero nos aproximaba. Yo, al menos, lo he contado siempre entre los hombres caros a mi corazón. Mis amigos podrían testificar si su nombre ha sido familiar en mis labios en nuestras tertulias intelectuales. Y su caballeresca conducta con nuestros delegados obliga profundamente nuestra gratitud. De hoy en adelante figurará Ud. al lado de Alberdi, entre los grandes argentinos amigos del Paraguay. $Y$ yo espero que cultivaremos nuestras relaciones manteniendo una activa correspondencia. Porque uno y otro tenemos una gran misión que cumplir, la de vincular a nuestras patrias, reconciliándolas en el respeto a lo que constituye su honor y su gloria y sacudiendo sus odiosos prejuicios que nos legaron generaciones envenenadas por pasiones que ya no tienen razón de ser. Gracias, pues, por todas sus bondades, gracias, pues, por sus infinitas gentilezas y crea que siente por usted el más sincero afecto, su amigo paraguayo (BNP-CJEO, Correspondencia Oficial y Privada, Carpeta XXXVI).

Para ese entonces Peña ya había desarrollado la mayor parte de su trayectoria vital y era una figura reconocida de los círculos intelectuales argentinos. Según se ha apuntado, desde 1906 formaba parte de la Junta de Historia y Numismática Americana, y había sido secretario general de la Comisión Nacional del Centenario

\footnotetext{
$\overline{10}$ Este libro corresponde al volumen 7 publicado por la Biblioteca paraguaya del Centro de Estudiantes de Derecho, integrando así una colección en la que le habían precedido títulos como Nuestra epopeya (guerra del Paraguay) (1919), de Juan E. O'Leary, La causa nacional, ensayo sobre los antecedentes de la guerra del Paraguay (1864-70) (1919), de Justo Pastor Benítez, Rodó: homenaje de la juventud del Paraguay (1919), La cuestión social (1919) y Visiones uruguayas (impresiones de un viaje) (1920), de Juan Vicente Ramírez, y Aurora, del mismo Juan Stefanich (1920).
} 
de la Revolución de Mayo, también había fundado la revista Atlántida (1911), así como el Ateneo Nacional (1913). Tenía en preparación, la edición de las "Memorias de Alberdi", un conjunto de escritos distribuidos en tres tomos que pretendían abarcar los sucesos de su vida entera, entre 1810 y 1884 . Habiendo sabido por el mismo O'Leary sobre la existencia del conjunto de cartas de Alberdi dirigidas a Gregorio Benites durante la guerra del Paraguay y en los años posteriores, Peña le escribió a O'Leary manifestándole que no se decidía a hacer públicos los tres tomos por faltarle esa correspondencia:

El tiempo pasa, los años transcurren, la vejez viene y nosotros nos
quedamos cediendo el campo a enemigos comunes. Los que vengan
después de nosotros, de usted y de mí, para hacer más real mi interrogación
¿tendrán la facilidad y el entusiasmo, el valor y los medios que nosotros
poseemos para hacer la misión? De usted depende, pues, que lancemos
a América un libro más sobre Alberdi, con su parte sobre Paraguay, y este
será de combate y de interés porque será pura autobiografía (BNP-CJEO,
Correspondencia Oficial y Privada. Carpeta XXXVI).

Las cartas de Alberdi no llegaron a manos de Peña. Tampoco O'Leary completó, en los años siguientes, la escritura de una biografía de Alberdi, ni la publicación de esas misivas, aunque mantuvo y reiteró su propósito en no pocas ocasiones, sobre todo cuando se renovaba la polémica en torno a la actuación del jurisconsulto argentino a favor del Paraguay.

\section{6}

\section{Tercer momento: Peña, O'Leary y los "procesados de la historia"}

La última carta de la relación epistolar Peña-O'Leary que se ha encontrado, fue escrita por el historiador paraguayo en 1928. La reanudación del contacto es motivada en este caso por un escrito de Peña relativo a Francisco S. López.

O'Leary había publicado, en 1920, El Mariscal López, con el sello editorial del diario La Prensa. El contenido estaba dividido en 26 capítulos a lo largo de 374 páginas. Si bien el autor sostuvo que se realizó una tirada de 2000 ejemplares del libro no existen, por el momento, constancias de su recepción en el espacio cultural paraguayo como tampoco ha sido posible, hasta ahora, determinar circuitos de su comercialización.

Cinco años después, en 1925, O'Leary fue designado por el gobierno de Eligio Ayala como Encargado de Negocios de Paraguay en España. Instalado en Madrid, conoció y entabló amistad con el escritor mejicano Carlos Pereyra y con los escritores venezolanos Rufino Blanco Fombona y Laureano Valenilla Lanz, entre otros. Todos ellos escribían y publicaban en la Editorial América, que fundara Fombona en la capital española. En este contexto, O'Leary logró publicar una segunda edición de la biografía sobre López, a la que tituló El Mariscal Solano López y que fue prologada por Rufino Blanco Fombona. En esta nueva entrega añadió un capítulo, con lo que la obra presentaba 27 capítulos con un total de 457 páginas. Así, si en la primera edición el contenido concluía con los titulados "La inmolación del héroe" y "Síntesis final de su vida", en 
la más reciente se intercalaba el denominado "La glorificación del vencido". ${ }^{11}$ El propósito principal del texto consistía en la reivindicación de la figura y la actuación de Francisco Solano López y en demostrar la injusticia de los atributos de bárbaro, déspota y sanguinario con los que la literatura histórica, sobre todo en Argentina, caracterizaban a López hasta entonces. De carácter ensayístico, sin el menor sustento de documentos ni de otras fuentes, O'Leary inició con esta obra la reivindicación de Solano López, un proceso que culminaría con la heroificación, en 1936, cuando se lo declararía, oficialmente, héroe nacional.

O'Leary residía, en esos años, en Madrid, en calidad de Encargado de Negocios de Paraguay, pero realizaba frecuentes viajes y estadías en París, donde con otros letrados paraguayos habían establecido la Editorial de Indias, dedicada a la publicación de obras de y sobre Paraguay. Al momento de conocer el escrito de David Peña sobre López, O'Leary divulgaba su biografía sobre el mariscal Solano López (1925). Estas circunstancias explican que se manifestase conmovido por la lectura del texto de Peña y encontrase natural la posición adoptada por quien otrora iniciara la defensa de Facundo Quiroga, como si un nexo invisible uniera a todos los repudiados de la historia, y los hiciera a todos igualmente merecedores de la reivindicación por parte de los historiadores identificados con una corriente de revisión del pasado:

No podía hablar en otra forma el gran justiciero de la historia argentina, el intrépido vindicador de la memoria de Alberdi, el que arrojó las primeras flores de piadosa recordación sobre la tumba sin nombre de Facundo Quiroga... Un espíritu selecto como el suyo no podía caer en la vulgar diatriba, ni, mucho menos, dejar de sentir la grandeza del hombre formidable a quien Buenos Aires juró un día "eterna gratitud", del patriota implacable que todo lo sacrificó por su patria, muriendo con la espada en la mano en la heroica actitud de los más bellos tipos de la historia del mundo. No! Un David Peña tenía que hablar así, sin temores, sin preocupaciones, libre de prejuicios, aplaudiendo al pueblo paraguayo que hoy alza orgulloso sobre su cabeza la figura del varón fuerte que fue la encarnación de su derecho y el representante armado de su soberanía (ANH-FDP, Carpeta 3, De Juan E. O'Leary a David Peña, Madrid, agosto 28 de 1928).

A través de estas palabras se trasunta la profunda admiración de O'Leary hacia el autor en cuyas ideas puede filiar su propia posición historiográfica. Se refleja, asimismo, el claro sentido de exaltación patriótica que el propio O'Leary le ha conferido a su labor como historiador, y la operación que ha puesto en marcha para trasformar a López en héroe máximo y mártir sacrificado de su nación.

O'Leary se siente el intérprete y portavoz de los sentimientos de su "patria adolorida", cuando agradece en nombre de ésta a Peña por sus juicios ecuánimes sobre el cuestionado gobernante paraguayo.

\footnotetext{
${ }_{11}$ En España la obra fue editada por la imprenta Félix Moliner. Hemos trabajado los ejemplares pertenecientes a la biblioteca personal de O'Leary, en la Biblioteca Nacional del Paraguay. Parece interesante resaltar que, en la segunda edición, el autor se ocupó de compilar exposiciones, opiniones y juicios de letrados y de gobiernos americanos que en distintos momentos reconocieron la actuación del Mariscal López, como el argentino Juan Bautista Alberdi, el uruguayo Luis Alberto de Herrera, el venezolano Laureano Vallenilla Lanz y el guatemalteco José Joaquín Palma, entre otros.
} 
Finalmente, O'Leary aprovecha su carta para enviarle a Peña dos libros suyos que espera que lea $y$, de ser posible, comente. Lejos de buscar una actitud de prescindencia e imparcialidad frente al pasado, el autor paraguayo le confía a Peña en la intimidad de su intercambio epistolar "el dolor que trasuntan esas páginas". Espera encontrar comprensión y empatía de parte de Peña, y le especifica que en uno de ellos encontrará el texto íntegro de la carta de López a su hijo.

Dos años después, a los 68 años de edad, falleció David Peña. En el seno de la Junta de Historia y Numismática Americana, Peña fue recordado por Octavio Amadeo -en un sentido similar al que le había atribuido O'Leary en su carta de 1928- como el "abogado de los grandes procesados de la historia" y evaluó, con la perspectiva del tiempo transcurrido, el significado de su obra, diciendo que

Su Quiroga fue un golpe de piqueta a lo consagrado, a lo que parecía intangible, al magister dixit. [...] Peña cometió esa irreverencia patriótica; proclamó el libre examen, exigió la revisión de muchos fallos. Fue una novedad simpática. Hoy ya no se discute esa revisión; está decretada por todos (BJHNA 1936, vol. VIII, p. 220).

\section{Conclusión}

El estudio del intercambio epistolar entre David Peña y Juan E. O'Leary nos ha permitido ponderar la importancia de los discursos producidos en el ámbito privado para una mejor explicación de procesos historiográficos y de las concepciones del pasado de los historiadores. En el caso de las cartas remitidas por O'Leary allanan, entre otros asuntos, la reconstrucción del trayecto iniciático de su revisión de la historia, un movimiento que principió en Paraguay entre siglos diecinueve y veinte como respuesta a las visiones del pasado dominantes en su país, de manera particular sobre las causas y el desarrollo de la guerra contra la Triple Alianza (1864-1870), la censura a la memoria del Mariscal Solano López, y al socaire de su impugnación al orden político emergente tras la revolución de 1904 . En el caso de las de David Peña permiten perfeccionar su itinerario intelectual como así también complejizar los orígenes del revisionismo en Argentina.

Aunque no ha sido posible desarrollar por completo el ejercicio comparativo entre las biografías construidas por Peña y por O'Leary, aparece con claridad el influjo que el primero ejerció sobre la obra del segundo. De hecho, en los años que siguieron a la publicación de la biografía de Francisco Solano López, se convertiría en el historiador más influyente del Paraguay.

\section{Referencias bibliográficas}

AMARAL, Raúl. El Novecentismo paraguayo. Hombres e ideas de una generación fundamental del Paraguay. Asunción: Servilibro, 2006.

BREZZO, Liliana M. Juan E. O'Leary. El Paraguay convertido en pluma de acero. Asunción: El Lector, 2011a.

. Representaciones del Paraguay en el Centenario de su independencia. In: MELIÁ, Bartomeu (coord.). Otras historias de la independencia. Asunción: Taurus, p. 39-63, 2011b. 
- Vivimos en tiempo de las más grandes reivindicaciones. Las cartas privadas entre dos letrados paraguayos durante la primera década del siglo XX: Gregorio Benites y Juan E. O'Leary. Revista Paraguaya de Sociología, n. 141, p. 193- 233, 2012.

Boletín de la Junta de Historia y Numismática Americana (BJHNA), Buenos Aires, 1936

BORKOSKAY, María Mercedes. Epistolarios: la intimidad expuesta. Cahiers du GRIAS, n. 10, p. 27-45, 2002.

CABALLERO CAMPOS, Herib. Juan Stefanich, el canciller de la revolución. Asunción: El Lector, 2011.

CAPDEVILA, Luc. Una guerra total: Paraguay, 1864-1870: Ensayo de historia del Tiempo presente. Asunción: CEADUC, 2010.

CENTURIÓN, Carlos R. Historia de la Cultura Paraguaya. Asunción: Biblioteca Ortiz Guerrero, 1961.

CHIARAMONTE, José Carlos. Revisión del revisionismo: orígenes del revisionismo histórico argentino. In: Usos políticos de la historia: Lenguaje de clases y revisionismo histórico. Buenos Aires: Sudamericana, 2013.

DEVOTO, Fernando y PAGANO, Nora. Historia de la Historiografía Argentina. Buenos Aires: Sudamericana, 2010.

GOMEZ LEZ, Osvaldo y ZARZA, Miguel (comp.). Pensadores (as) del 900. Asunción: CIF, 2013.

GONZÁleZ de BOSIO, Beatriz. Periodismo Escrito Paraguayo. 1845-2001. Asunción: Intercontinental, 2008.

La Época, Buenos Aires.

MESTRE SANCHÍS, Antonio. La carta, fuente de conocimiento histórico. Revista de Historia Moderna, n. 18, p. 13-26, 2000.

MICHELETTI, María Gabriela. "Facundo Quiroga rehabilitado". Una aproximación al contexto de producción, repercusiones y aportes historiográficos del libro de David Peña (1906). Boletín del Instituto de Historia Argentina y Americana "Dr. Emilio Ravignani", n. 42, p. 125-153, 2015.

O’LEARY, Juan E. El Mariscal López. Asunción: La Prensa, 1920.

EI Mariscal Solano López. Madrid: Félix Moliner, 1925.

Recuerdos de Gloria. Compilación y edición a cargo de Ricardo Scavone Yegros. Asunción: Servilibro, 2008.

ORTEGA, Soledad. Reflexiones en torno a los epistolarios. Revista de Occidente, Madrid, n. 120, 1991.

Patria, Asunción. 
PEÑA, David. Contribución al estudio de los caudillos argentinos. Juan Facundo Quiroga: Conferencias en la Facultad de Filosofía y Letras (con ampliaciones y notas). Buenos Aires: Coni, 1906.

REALI, María Laura. Entre historia y memoria: la producción de Luis A. de Herrera en los orígenes de un relato revisionista sobre la Guerra del Paraguay. Nuevo Mundo, Mundos Nuevos, Coloquios, puesto en línea el 02 feb. 2006. Disponible en: http://nuevomundo.revues.org/1725.

RUBIO GARCÍA, María Sol. La temprana revalorización de Juan B. Alberdi en los escritos de David Peña. In: III Jornada de Discusión de Avances de Investigación en Historia Argentina: Fuentes, Problemas y Métodos. Anales... Rosario: Instituto de Historia, UCA-IDEHESI-CONICET, 2010.

SCAVONE YEGROS, Ricardo (comp.). Polémica sobre la historia del Paraguay. Estudio preliminar de BREZZO. Asunción: Editorial Tiempo de Historia, 2012.

STEFANICH, Juan. Alberdi, la Argentina y el Paraguay: al margen de una misión. Asunción: Talleres Nacionales de H. Graus, 1920.

VELÁZQUEZ, Rafael Eladio. Breve historia de la Cultura en el Paraguay. Asunción: Edición autor, 1999.

\section{Archivos}

30 Academia Nacional de la Historia, Fondo David Peña (ANH-FDP).

Archivo del Museo Histórico Provincial de Rosario "Dr. Julio A. Marc" (AMHP), Documentos manuscritos clasificados por Legajos personales: David Peña.

Biblioteca Nacional del Paraguay, Colección Juan E. O'Leary (BNP-CJEO). 